\title{
Research Square \\ Factors Driving the Spatiotemporal Variation of Dissolved Organic Carbon Flux from Croplands in the Midwestern USA
}

\section{Yong Qian Tian ( $\nabla$ yong.tian@cmich.edu )}

Central Michigan University

\section{Qian Yu}

University of Massachusetts Amherst

\section{Hunter Carrick}

Central Michigan University

\section{Brian Becker}

Central Michigan University

\section{Remegio Confesor}

Norwegian Institute of Bioeconomy Research: Norsk Institutt for Biookonomi

\section{Mark Francek}

Central Michigan University

\section{Olivia Anderson}

Central Michigan University

\section{Research Article}

Keywords: dissolved organic carbon, inland water, anthropogenic activity, crop residue management, baseflow, agricultural landscape, hydrological modelling

Posted Date: January 14th, 2022

DOI: https://doi.org/10.21203/rs.3.rs-1223810/v1

License: (c) (1) This work is licensed under a Creative Commons Attribution 4.0 International License. Read Full License 
1 Factors Driving the Spatiotemporal Variation of Dissolved Organic Carbon Flux from Croplands in the

2 Midwestern USA

3 Yong Q. Tian ${ }^{\mathrm{a} *}$, Qian $\mathrm{Yu}^{\mathrm{b}}$, Hunter J. Carrick ${ }^{\mathrm{c}}$, Brian L. Becker ${ }^{\mathrm{a}}$, Remegio Confesor ${ }^{\mathrm{d}}$, Mark Francek ${ }^{\mathrm{a}}$, and

4 Olivia C. Anderson ${ }^{\mathrm{c}}$

$5 \quad a^{*}$ : Department of Geography and Environmental Studies \& Institute for Great Lakes Research, Central

$6 \quad$ Michigan University, MI 48858

7 Email: yong.tian@cmich.edu

8 b: Department of Geosciences, University of Massachusetts-Amherst, Amherst, MA 01003,

9 c: Department of Biology \& Institute for Great Lakes Research, Central Michigan University, MI 48858

10 d: Environment and Natural Resources, Norwegian Institute of Bioeconomy Research, Norwegian

11

12

* Corresponding author 
13 Abstract:

14 Improving understanding of dissolved organic carbon (DOC) cycling from farmlands to rivers is a

15 challenge due to the complex influence of farming practices, the hydrology of predominantly flat

16 lowlands, and seasonal snowpack effects. Monthly field DOC concentrations were measured throughout

17 the year at sub-basin scale across the Chippewa River Watershed, which falls within the Corn Belt of the

18 Midwestern United States. The observations from croplands were benchmarked against the data sampled

19 from hilly forested areas in the Connecticut River Watershed. The Soil Water Assessment Tool

20 (SWAT) was used to simulate daily soil water properties. This method tests for a framework for using

21 the combination of new field data, hydrological modelling, and knowledge-based reclassification of

22 Land Use/Land Cover (LULC) to analyze the predictors of both the spatial and temporal changes of

23 DOC over farmlands. Our results show: 1) DOC concentrations from cropland baseflow were

24 substantially high throughout the year, especially for spring runoff/snowmelt scenarios, 2) gradient

25 analysis with spatial factors only was able to explain $\sim 82 \%$ of observed annual mean DOC

26 concentrations, and 3) with both spatial and temporal factors: [Evapotranspiration, Soil Water, and

27 Ground Water], the analysis explained $\sim 81 \%$ of seasonal and $\sim 54 \%$ of daily variations in observed DOC

28 concentrations.

29

30 Keywords: dissolved organic carbon, inland water, anthropogenic activity, crop residue management,

31 baseflow, agricultural landscape, hydrological modelling 


\section{INTRODUCTION}

Terrestrial organic carbon in the dissolved form (DOC) is easily transported to inland or coastal waters via hydrological processes (Dusek et al. 2017; Heppell et al. 2017). Excessive riverine carbon has a pronounced impact on aquatic ecosystems via processes such as amplifying microbial activity, diminishing the quantity and quality of light penetrating the water column, and controlling toxic metal availability (Butman and Raymond 2011; Spencer et al. 2013; Stedmon et al. 2006). As a major use of land (Ellis et al. 2010), agricultural landscapes are a significant source of DOC in freshwater ecosystems (Tranvik 2014). Recent studies raised a public health concern that rivers receiving runoff from croplands have elevated DOC concentrations at regional and worldwide scales (Bhattacharya and Osburn 2020; Qiao et al. 2017). DOC originating from croplands are enriched in aromatic structures and exhibit high labile properties, thereby significantly affecting freshwater nutrient pathways (Bhattacharya and Osburn 2020; Holgerson and Raymond 2016; Kellerman et al. 2020; Tranvik 2014).

In recent decades, there has been an increased interest in studying terrestrial carbon-source dynamics and their impact on freshwater interactive processes (Heppell et al. 2017). As such, studies have made significant progress towards gaining a better understanding of the impacts of climate change and extreme storm events on variations of riverine DOC concentrations originating from terrestrial environments (Kellerman et al. 2020). However, these studies are often limited in scope because they were set at entire river basin scales without considering the heterogeneity and do not include sub-basin land-surface characteristics and hydrological processes. In addition, these studies have largely focused on semi-natural habitats involving little or no agriculture such as estuarine wetland, scrub-shrub, and forested areas(Raymond and Saiers 2010; Rudolph et al. 2020; Tian et al. 2012). Studies focused on forested landscapes are typically dominated by sloped landscapes that generate DOC fluxes predominantly through surface runoff (Raymond and Saiers 2010; Singh et al. 2015). A representative 
57 DOC model for studying hilly forested regions is the Integrated Catchments model for Carbon (INCA-

58 C) (Futter et al. 2011). By using the INCA-C model, a study revealed that variations in DOC

59 concentrations was primarily driven by soil temperature and surface runoff over forested, mountainous

60 watersheds in Sweden (Clark et al. 2007; Fu et al. 2019; Pers et al. 2016). However, several other

61 studies further clarified that event-based fluxes do not necessarily occur without baseflow during rainfall

62 events; rather, event-based flows usually account for both surface runoff and baseflow during, and a few

63 days after, a rainfall event ( $\AA$ gren et al. 2008; Olsson et al. 2009). Therefore, DOC models that are based

64 on measurements sampled from semi-natural habitats are not readily adaptable to agricultural landscapes

65 in which carbon sources are typically more heavily influenced by complex anthropogenic factors, have a

66 higher degree of heterogeneity of land cover types, and exhibit the major role of baseflow in

67 lowland/flatland hydrological processes.

The DOC dynamics in streamflow generated from agricultural landscapes are significantly different than those reported for semi-natural habitats. This is especially true for the Corn Belt region of the Midwestern USA, where flatland hydrology dictates temporal variations in DOC concentrations via

71 baseflow rather than overland surface runoff (Qiao et al. 2017). This is in sharp contrast to hilly forested

72 areas where the majority of annual DOC fluctuations are dictated predominantly by surface runoff

73 during rainfall events. Even over forested lands, it has been reported that low-flow conditions are ideal

74 in order to best understand the transport processes of nutrients (e.g., $\mathrm{N}$ and $\mathrm{P}$ ) from the soil profile and

75 land surface (Lindström et al. 2010; Pers et al. 2016).

In general, the factors driving spatiotemporal variation of DOC concentrations in streams of

77 croplands between rainfall events are not well understood. These temporal DOC variations are

78 assumably controlled by soil properties such as organic matter content, level of saturation, and

79 temperature. The spatial variations are likely associated with heterogeneity of the landscape, such as the 
80 typical patchwork of small water bodies, wetlands, forest, and a broad range of crop density. More

81 variation or heterogeneity is introduced when considering the varied crop residue management policies

82 implemented by land managers. It remains largely unproven if both the spatial and temporal variations

83 of DOC fluxes from croplands to receiving waters can be reliably quantified, and what the appropriate

84 sub-basin scales are for quantifying these spaciotemporal variations

The goal of this study is to analyze how DOC concentrations originating from crop-dominant

86 lowlands vary by season and spatial distribution. We aim to identify a range of potential drivers that are

87 useful to modelling the spatial disparities and trends of DOC variations instead of using soil C:N ratio as

88 a surrogate (Aitkenhead-Peterson et al. 2003). The research niche includes the incorporation of detailed

89 hydrologic variables, the adaptation of high spatial-resolution land surface features, and the collection

90 and utilization of primary field observations. This study is focused on identifying a workable

91 spatiotemporal scale of both field observations and quantitative analysis of DOC source dynamics, fate,

92 and transport processes. This research focus is both novel and urgent because DOC export from

93 agricultural landscapes occurs at the expense of the water quality of adjacent freshwater systems and to a

94 lesser extent the land sustainability. Detrimental agricultural land management policies and practices can

95 inherently lead to degraded water quality through both physical and biochemical processes(Jones et al.

96 2004; Jones and Knowlton 2005; Monaghan et al. 2007; Valentin et al. 2008). Clearly, DOC is part of a

97 delicately balanced synergistic system and thus, modelling the concentration of DOC in lakes and rivers

98 can provide a useful index of land-water ecology (Gómez-Gener et al. 2021).

\section{MATERIALS AND METHODS}

100

101 Study site: 
Two contrasting study sites (cropland versus sloped forestland) were referenced in this study to

103 allow direct comparison of DOC dynamics from croplands to a more homogeneous, forested landscape.

104 The primary study site consisted of the Chippewa River watershed, which is one of the three tributaries 105 draining the western portion of the larger Saginaw River watershed. The Saginaw River ultimately 106 empties into Saginaw Bay, Lake Huron, which is one of the most bio-productive coastal regions in the 107 entire Great Lakes Ecosystem (Millie et al. 2006). The Chippewa watershed cuts across the Lower 108 Peninsula of Michigan and extends nearly 92 miles to Midland, Michigan, flowing predominantly 109 eastward and ultimately merging with the Tittabawassee River. The croplands in our primary study site 110 were dominated by row crops of corn, soy, wheat, and sugar beets, that were situated adjacent to mixed 111 woodlots and wetlands, with a small proportion of lands dedicated to hay production and areas of 112 development. The topography (mean slope $<0.3^{\circ}$ ), and climate in the primary study site were typical to 113 the flat lowlands of the midwestern United States. In-situ DOC samples (153) were collected monthly at 114 key locations across the Chippewa River watershed from 2012 to 2014.

115 The secondary study site for this study included five largely forested sub-basins within the greater 116 Connecticut River Watershed, which is the longest river in the northeastern United States. DOC samples 117 extracted from these forested sub-basins provided direct comparisons to those collected in the primary 118 study site. The Connecticut River Watershed is one of the larger watersheds in the Northeast, draining 119 approximately 11,000 square miles. In-situ DOC samples (125 samples) were collected monthly from 1202011 to 2016 across these five forested sub-basins within the Connecticut River Watershed (Li et al. 121 2018). Two of the five sub-basins had landcover types dominated by northeastern deciduous forests. 122 Northeastern conifer forests were the dominant vegetation in two of the sub-basins. The fifth sub-basin's 123 land cover was classified as a northeastern conifer/deciduous mixed forest. These 125 forested, in-situ 
124 field observations collected across multiple years and seasons were paramount to better quantify the 125 significant DOC contributions from croplands in comparison to forested landscapes.

127 Field Sample Protocols

128 There were 278 water samples collected in total, from 26 sampling locations via 43 field visits 129 spread between the two study sites. Within the primary study site, a range of locations were selected and 130 organized into two sampling groups (crop dominated and mixed croplands) as displayed in Figure 1. The

13113 sampling locations (IDs 1-13) associated with the first group focused on crop-dominated drainage 132 sub-basins. The 8 sampling locations (IDs 14-21) associated with the second group was added to include 133 drainage sub-basins dominated by the croplands mixed with a large proportion of forests and wetlands. 134 Monthly field visits were arranged between rainfall events to best reflect seasonal variations and to 135 reduce the influence of any single event. The entire cropland field campaign ran for 14 months 136 beginning in October 2012 and ending in January 2014. Field sampling activities were primarily 137 conducted during the spring and fall when soil biochemical processes and nutrient fluxes are more 138 prevalent(Sela et al. 2019; Sharratt et al. 1998). DOC concentrations are generally elevated in the 139 springtime months due to snowpack dependent biochemical processes, soil moisture conditions, and 140 runoff from snowmelt (Qiao et al. 2017). DOC concentrations are also elevated in the autumn months 141 when crop biomass is at its peak and when such biomass is actively manipulated due to harvest, residue 142 management practices, and fall tillage(Kelly et al. 2015; Vetsch and Randall 2002). A reduced number 143 of field samples were collected for the purpose of analyzing the transition of DOC concentrations 144 between seasons. In total,153 water samples were collected to satisfactorily quantify seasonal patterns in 145 DOC variation within receiving waters. 


\section{Laboratory Protocols to Estimate DOC concentration}

148 Field samples were obtained from all sampling locations using clean $500 \mathrm{~mL}$ bottles (acid washed) 149 to collect stream water for DOC analysis. Bottles were fully immersed while capping to ensure that no 150 air remained. The samples were immediately stored on ice until arrival at the lab for immediate 151 filtering. Water samples were filtered through pre-combusted glass-fiber filters (nominal $0.7 \mu \mathrm{m}$ pore 152 size) to remove any non-dissolved organic matter, and the filtrate was then stored (acidified and 153 refrigerated) until analysis for DOC content. All Laboratory processes were completed within 12 hours 154 of sample collection. The DOC concentration of each water sample was measured using a Shimadzu 155 TOC-V analyzer with high temperature combustion (Vlahos et al. 2002). For each, $50 \mu$ l injections of 156 sample water was combusted at $800{ }^{\circ} \mathrm{C}$, from which the DOC concentration was calculated from the 157 resultant $\mathrm{CO}_{2}$ yield and measured with a non-dispersive infrared detector.

\section{Land Cover Composition}

National Land Cover Data (NLCD) data from 2011 was used because this date was closest to our sampling dates (2012-2014). The original baseline NLCD data referenced 13 land cover categories. We reclassified these baseline land cover data into three more broadly defined classes according to their general DOC transforming rates based on preliminary modelling runs (Figure 2). The percent-areal composition of the three new classes extracted from the NLCD data were calculated for each drainage

165 sub-basin in the primary study site and are shown in Table 1 . These data were used to analyze DOC 166 dynamics at the sub-basin level. It is important to note that land cover data was needed for the entire 167 area draining to an individual sampling location and not just the sub-basin in which the sampling 
168 location resided. For instance, sampling point 15 receives runoff not only from its home (immediate)

169 sub-basin, but also from upstream sub-basins that contained points 16, 17 and 18.

171 Hydrological Modeling

172 The Soil Water Assessment Tool (SWAT) was used to generate daily hydrologic characteristics for 173 all sub-basins of the primary study site. We examined the simulated outputs to identify which variables, 174 if any, were significant estimators of seasonal variation in DOC concentrations from croplands. The 175 SWAT model is recognized worldwide as one of the most effective tools for estimating hydrological 176 processes from agricultural lands (Arnold and Fohrer 2005; Olaoye et al. 2021; Tian et al. 2012). For 177 this study, we implemented SWAT using 38 years of daily hydrologic input data spanning from 1981 to 178 2018. In addition, spatially explicit, high resolution $\left(4 \mathrm{~km}^{2}\right.$ grid $)$ daily weather forcing data 179 (precipitation, maximum temperature, and minimum temperature) were downloaded from the PRISM 180 website (https://prism.oregonstate.edu/recent/) and also used as SWAT inputs. Daily discharge flow of 181 the Chippewa River was obtained from the USGS 04154000-gauge station and used to calibrate the 182 SWAT model. LULC types were extracted from NCLD 2011 as described above and used as inputs. 183 Soil input parameters were extracted from SWAT's built-in STATSGO data. Elevation data were 184 extracted from a 30m Digital Elevation Model (DEM) of Isabella County, Michigan. As a result, the 185 SWAT model delineated our primary study site into 126 sub-basins.

Next, Chippewa River daily flow data were categorized into high (top 10 percentile), medium (10th-50th percentile), and low (lowest $50^{\text {th }}-100^{\text {th }}$ percentile) flows. The SWAT model was then 189 calibrated through a multi-objective auto-calibration for these three flow regimes for the period from 1902011 to 2018 using the method developed by (Confesor Jr and Whittaker 2007). The overall daily Nash- 
191 Sutcliffe model efficiency coefficient (NSE) was 0.67 and the corresponding $\mathrm{R}^{2}$ was 0.886 . The

192 simulated hydrologic properties for each of the 126 SWAT modeled sub-basins were used as

193 independent variables for quantitative analysis of daily DOC observations.

Exploratory Statistical Analysis

Multiple linear regression analysis was used to explore which independent variables were most 197 relevant in explaining variation in DOC concentrations at various spatial and temporal scales. In 198 essence, these linear regressions aimed to fit observed/sampled DOC data to a linear equation with $m+n$ 199 independent variables, where $m$ is the number of variables associated with the characteristics of each 200 drainage sub-basin and $n$ is the number of temporal/seasonal variables. The specification of the linear 201 model was as follows:

$$
y(i, t)=c+\sum_{j=1}^{m} \alpha_{j} x_{j}(i)+\sum_{k=1}^{n} \beta_{k} S_{k}(i, t)
$$

203 Let $\mathrm{X}(i)=\left[\mathrm{x}_{1}(i) \mathrm{x}_{2}(i) \ldots \mathrm{x}_{\mathrm{m}}(i)\right]$ be the $m$ exploratory spatial variables for the sub-basin associated 204 with sampling location $i$ for $i=1 \ldots \mathrm{L}$. L is the number of sampling locations. Similarly, let $S(i, t)=$ $205\left[s_{1}(i, t), s_{2}(i, t), \ldots s_{n}(i, t)\right]$ be the $n$ exploratory seasonal (temporal) variables for the sub-basin $i$ and Julian 206 day $t$, for $t=1,2 \ldots$ Q. Q is the last Julian day of field sampling visits. Each variable set X $(i)$ were split in 207 three categories: land cover (e.g., percent cropped area, percent forested), soil properties (e.g., percent 208 silt, percent organic matter), and geomorphology (e.g., sub-basin area, average slope). The spatial 209 variables were derived from each drainage area. The seasonal variables $S(i, t)$ were split into two 210 categories: hydrologic characteristics (e.g., SW: soil water content, PET: potential evapotranspiration, $211 G W$ : ground water volume) and weather inputs (e.g., point specific precipitation and temperatures). The 212 observed DOC, $y(i, t)$ corresponded with all sampling locations $i$, and the Julian days $t$ of field visits. 
213 The observed values $y(i, t)$ for all $i$ s and $t$ s were fitted to eq. 1 for estimating the parameters

$c, \alpha_{1}, \alpha_{2}, \ldots, \alpha_{\mathrm{m}}, \beta_{1}, \beta_{2}, \ldots, \beta_{\mathrm{n}}$

215 Statistical metrics used to evaluate relative importance and/or inclusion of variables into the models

216 were $p$-value, coefficient of determination $\left(\mathrm{R}^{2}\right)$, and $\mathrm{F}$ values reflecting the overall significance of each

217 regression model. An alpha of 0.05 was used as the threshold to determine if any one variable was

218 statistically meaningful. The analysis included all exploratory variables (in varying combinations) within

219 each category (temporal, spatial, physical, and biological). Our objective was to identify which variables

220 were significant at various temporal scales (i.e., daily, monthly, or annually). Accordingly, all

221 associated data had to be averaged when moving to a more course temporal scale. For example, $>30$

222 daily hydrologic variables were averaged to yield a single monthly value. Similarly, 365 daily

223 hydrologic variables were averaged to yield an annual average. Ultimately, a variety of variables were

224 fit to both raw and averaged (monthly and yearly) DOC observations to obtain the desired coefficients of

225 the linear model.

One of our research objectives was to evaluate the appropriate spatial scale (i.e., contributing

228 hydrologic areal extent) for quantifying the inherent relationship between a variety of independent 229 variables and the variation of observed DOC concentrations from cropland areas. Here, we designated 230 stream segment $i$ and sub-basin $i$ as the immediate stream segment and sub-basin in which the sampling 231 location $i$ resides. With this designation, this study tested two spatial scale scenarios: 1 st-order 232 extended sub-basins and non-extended drainage areas. All 1st-order extended sub-basins met one of the 233 following two criteria: (1) all sub-basins associated with sampling sites within a 1st-order stream, such 234 as sampling locations 4, 6, 7, 9, 10,11, 13, 16, 18, 19, and 20, or (2) all sub-basins associated with 235 sampling sites within a 2nd or 3rd order stream if they had the same dominant land cover as all their 
upper-tributary sub-basins. Sampling locations 5, 15, and 17 met this second criterion and were

237 designated as extended drainage sub-basins. For example, sub-basin 5 resides in a 2nd-order stream and 238 its dominant land cover is identical to that of its upper tributary sub-basin, which in this case was sub239 basin 4 (1st-order). Thus, the modelled drainage area associated with sampling location 5 included both 240 the areal extent of the upstream 1st-order sub-basin 4 and its immediate 2 nd order sub-basin 5.

241 Therefore, the extended sub-basins in this project consisted of 14 sub-basins: 4, 6, 7, 9, 10, 11, 13, 16, $24218,19,20,5,15$, and 17 . The remaining 7 sample locations $(1,2,3,8,12,14$, and 21$)$ are associated to 243 the non-extended drainage areas.

\section{RESULTS AND DISCUSSION}

247 and significance between a variety of independent, spaciotemporal variables and observed DOC

248 concentrations in cropland areas. We present pertinent results and related discussion within four distinct 249 sections: 1) Spatial disparity of mean annual DOC, 2) Seasonal/temporal patterns from the observations 250 for both croplands and forested lands, 3) Variables useful to estimate spatial and temporal distributions 251 of DOC concentrations in streamflow throughout the year, and 4) A quantitative analysis of mean 252 monthly DOC trends.

254 1. Spatial disparity of mean annual DOC

255 DOC concentrations ranged from 5.5 to $10.5 \mathrm{mg} / \mathrm{L}$, and these values varied greatly across the 256 drainage sub-basins of the primary study area. Our results revealed that the DOC observations averaged 257 over the entire year for each sampling location were largely controlled by four spatial variables for the $2581^{\text {st }}$-order extended areas. Specifically, a resultant linear regression model (eq. 2) explained more than 
$25982 \%\left(\mathrm{R}^{2}{ }_{\text {adj }}=0.74\right)$ of mean annual DOC, $\bar{y}(i)$, the concentrations observed across 14 sampling locations:

$2604,5,6,7,9,10,11,13,15,16,17,18,19$, and 20 (Figure 3A).

261

$$
f(X)=0.52 c r p+1.19 f r t+0.52 w e t l+18.74 d u m-63.07
$$

262 Where the first three variables (i.e., crp, frt, wetl) were percent of crops, forest, and wetland, and dum 263 was the binary dummy variable useful for separating crops and mixed land covers $(\operatorname{crop}=1$, mixed $=0)$.

264 All coefficients for each of the four variables and the y-intercept were significant with respect to the 265 observed DOC data ( $\mathrm{p}$-values $<<0.05)$. The overall model explained a significant portion of variation in 266 DOC values $(\mathrm{F}=10.22, p$-value $=0.0021)$. The dummy variable used in this modeling effort played a 267 role as a constraining condition. The dummy variable expanded the capability of the linear regression for 268 these complex scenarios of mixed land cover composition.

The positive coefficient for the variable crp shown above indicates a positive correlation between

271 DOC concentrations and crop density ( $c r p)$, as one might expect given that crop density and the

272 resulting residues usually increase DOC loadings (Tian et al., 2013). However, inspection of the 3-D

273 graph in Figure 3B clearly contradicts such a positive relationship, for the highest DOC values were

274 clearly associated with the low crp values. This negative correlation seemed to be regulated by a

275 geomorphological feature, $\operatorname{Ln}(A)$ which is the logarithm of the drainage areas.

The percent of crop land cover $(\mathrm{crp})$ is indeed positively correlated to $\operatorname{Ln}(A)$, which was not included

278 in eq. 2 for crop dominant areas because the $p$-value was slightly larger than the 0.05 threshold $(\mathrm{p}=$ 279 0.0638). Moreover, further inspection of the 3-D graph in Figure 3B also revealed that both $c r p$ and $280 \ln (A)$ have an inverse relationship to mean annual DOC. This result demonstrated the relative 281 importance of accounting for geomorphological parameters $(A)$ that appear to act at the scale of 
282 individual sampling locations. Interestingly, $\ln (A)$ was included in a linear model (eq. 3), once the $p$ 283 value threshold was relaxed to 90 percent ( $\mathrm{p}$-values $<0.1)$.

$$
f(X)=0.43 c r p+1.03 f r t+0.41 w e t l+16.01 d u m-0.45 \ln (A)-46.09
$$

in eq. 3. This spatial variable was helpful in estimating mean annual DOC concentrations in runoff from negative coefficient reflects the hydrologic processes occurring on and within the relatively larger and 291 flatter (i.e., equated to higher percentage of crops) sub-basin. The alteration of hydrologic processes 292 would result in the reduction of DOC concentrations because of the longer transport and residence time, 293 allowing for greater soil carbon adsorption and infiltration. The second model (eq. 3) explained DOC 294 observations better $\left(88 \%, \mathrm{R}_{\text {adj }}^{2}=0.69, p=0.001\right)$ than the model (eq. 2$)$ which did not directly reference 295 this geomorphologic variable, drainage area. modelling mean annual DOC concentrations at the individual sub-basin level. Verification of model 299 performance at the individual sub-basin level is indeed a necessary step before coupling multiple sub300 basins into a more integrative model for use at a larger or regional scale. In other words, integrative 301 modelling can indeed estimate DOC concentrations within high order stream segments by cumulatively 302 aggregating or mixing DOC loadings from modelled upstream sub-basins(Tian et al. 2002). This 303 integrative and hydrologically cumulative approach appears to better approximate the reality of how the 304 many interconnected watershed components exchange materials from 1st-order to higher-order 305 downstream receiving waters. 
Both our statistical analyses and encouraging modelling outputs of DOC dynamics at the annual scale advances the scientific communities understanding of how anthropogenic agricultural land use changes and related management practices can help to explain spatial disparities of DOC concentrations originating from croplands. Our results also highlight the need for comprehensive in-situ sampling

311 campaigns across different ecoregions and climatic zones to help fine tune regional and global models.

312 The variables identified in eqs. 2 and 3 are extractable from satellite images, which helps bridge the gap 313 from more localized modelling efforts to more regional and global spatial scales that take advantage of 314 remote sensing technologies. Thus, this investigation verified the feasibility of using easily-obtainable 315 satellite image data to detect DOC dynamics and to study the impacts of human activities and 316 management policies on both land sustainability and the ecology of freshwater habitats.

\section{Seasonal DOC trends from crop and forest lands}

Strong seasonal patterns in DOC concentrations were inherent in our data, and the associated driving

320 factors became readily apparent from the analysis of daily and monthly DOC export rates. The patterns

321 in Figure 4A describe the DOC observations averaged in each month from all sampling locations that

322 were in the $1^{\text {st }}$-order extended sub-basin scenario. Sampled peak DOC concentrations were not

323 associated with runoff events, because we purposefully established our sampling periods to occur

324 between rainfall and storm runoff events. Accordingly, modeled DOC concentration peaks were the 325 result of seasonal phenomenon and not just a single episodic event. Generally, snowpack elevates soil 326 water content during late winter and early spring (i.e., middle of March). It has been reported that high 327 soil moisture content enhances certain saturation-dependent metabolic processes and biogeochemical 328 reactions (Leakey et al. 2006) as well as increased accumulation of DOC in the topsoil (Ågren et al. 
329 2010). The seasonal peak observed in March corresponds well with baseflow resulting from snowmelt

330 which acts to flush DOC stored in the topsoil created by these saturation-dependent metabolic processes

331 and biogeochemical reactions. The high soil-water content (i.e., soil moisture) for the primary study site

332 in late winter and early spring were predicted quite well by the simulation results of the SWAT

333 hydrologic model (Figure 5). The SWAT model also accurately predicted the high soil water content

334 associated with winter snowpack and its subsequent spring melting. The seasonal accuracy of the

335 SWAT model stands to reason, given the promising calibration performance $\left(\mathrm{NSE}=0.66, \mathrm{R}^{2}=0.88\right)$

336 when referencing daily flow records for 38 years. As such, a slight spike in DOC concentrations (i.e.,

337 March) originating from these organic-rich croplands appeared to be triggered by the infiltration of

338 snowmelt and elevated soil water content, coupled with the with flat topographic characteristics of the

339 mixed drainage sub-basins (blue curve in figure 4A). The mixed drainage sub-basins have relatively less

340 area for crop residue accumulation across multiple years, due to their relatively large percentage of

341 forest and wetland land covers. Rich crop residue biomass is indeed the dominant anthropogenic source

342 of geochemically active and transformable DOC. Spring is a critical time of the year with respect to

343 benthic and shallow water habitat in relation to biological communities, aquacultural production, and

344 water quality to public health(Lehosmaa et al. 2018; Puczko et al. 2018), which corresponds to spikes in

345 DOC concentrations.

In contrast, an early spring DOC peak was not observed (Figure 4B) from the steep forested lands

348 of the second study site despite similar weather conditions. Traditionally, farming practices for both

349 sweet corn and dent corn leave most plant residues in the field, which greatly increases soil organic

350 matter (Guo et al. 2018; Motavalli et al. 1992; Oberle and Keeney 1990). These accumulated residues

351 enrich soil organic biomass more so than the leaf-liter fell from forest canopies in autumn (Du et al. 
352 2019). In addition, the increased slopes associated with these non-cropped, forested hills encouraged 353 direct surface runoff with limited water infiltration through the soil profile. Less infiltration results in 354 less DOC flux movements which corresponds to the lack of such a DOC peak in early spring for these 355 forested locations (Figure 4B).

Other DOC peaks matched well between the two study sites (crop versus forest) from May to December (correlation > 0.65). We feel confident that these parallel DOC export curves are seasonal effects rather than of individual storm events since the curves were derived from a large set of multiyear, independent field measurements (i.e., 50 field visits). DOC spikes in May were triggered by increased soil temperatures followed by elevated ground water volumes (Figure 4). It seems logical that soils at depth take a longer time to warm up than the land surface temperature. Thus, the flux of DOC stored in such soil profiles were delayed until May at-depth soil temperatures began to rise (Figure 4A). High ground water levels and low soil water content were exhibited from the late April to early May as simulated via SWAT (i.e., black curve in Figure 5). Further examination of Figure 5 revealed that higher DOC export for croplands compared to forested areas was partially due to the crop farming practices, namely tillage in preparation for spring seeding. The optimum corn planting period for much of Michigan is from the beginning to middle of May, and soil manipulations would inherently rise as fields are prepped for planting. Soil temperature combined with the elevated soil moistures associated with summer rains may affect the DOC peaks in August for both study sites. Higher temperatures are associated with higher rates of microbial activities and faster turnover of DOC in the Carbon cycle of organic soils(Bowering et al. 2020; Haaland and Mulder 2010). 
The mean monthly DOC concentration for croplands were more than 3-fold greater (Figure 4A)

375 compared with those for forestlands (Figure 4B) throughout the year. The monthly precipitation and

376 temperature patterns between the two study sites were very comparable. Therefore, the excessive soil

377 DOC production rates from croplands were caused by anthropogenic effects in terms of crop residue

378 accumulation and related break-down. Our previous study's preliminary mesocosm experiments

379 revealed that corn plants have a slower metabolic process for transforming foliar organic matter into the

380 dissolved form when compared to deciduous (D) and evergreen (E) foliage(Li et al. 2018). Figure 6

381 illustrates how DOC production rate changed for the same applied biomass (260-g dry biomass), the

382 same number of incubation days, and two different temperatures $\left(\mathrm{L}: 20{ }^{\circ} \mathrm{C}\right.$ or $\left.\mathrm{H}: 25^{\circ} \mathrm{C}\right)$ for these three

383 vegetation types. Figure 6 illustrates that DOC transformation (i.e., foliar to dissolved) rates were often

3842.5 times faster for forest foliage as compared to sweet corn foliage. Intuitively, the amount of organic

385 biomass of croplands must therefore be 5-6 times higher than that of forested lands to result in the 3-fold

386 greater DOC concentrations. Clearly both farming and crop residue practices cause increased DOC

387 concentrations originating from croplands as opposed to climate or temperature variations.

389 3. Variables attribute to spatial and temporal DOC variations in croplands

390 Seven variables were identified as being statistically significant in driving DOC variation (eq. 5) in

391 reference to finer spatial and temporal scales. Three out of these seven variables were related to seasonal

392 effects that acted to quantify combined hydrologic and climatic properties: soil water content ( $s w$ in

$393 \mathrm{~mm})$, ground water volumes ( $\mathrm{g} w$ in $\mathrm{mm}$ ), and potential evapotranspiration (pet in $\mathrm{mm}$ ). The remaining

394 four variables were related to the spatial characteristics of any given sub-basin (i.e., crp, frt, wetl and

$395 \mathrm{dum}$ ). Note that these spatial variables are the same as those found to be significant when analyzing 
mean annual DOC dynamics. Specifically, for an area draining to sampling location $i$, and at a particular 397 Julian day, $t$, seasonal variable set $\mathrm{S}$ and spatial variable set $\mathrm{X}$ are: $\mathrm{X}(i)=[\operatorname{crp}(i), \operatorname{frt}(i), \operatorname{wetl}(i)$, and $\operatorname{dum}(i)]$ for all $i=4,5,6,7,9,10,11,13,15,16,17,18,19,20$

For the purpose of statistical data exploration, the linear regression was based on daily data $\mathrm{X}(i)$ for

\section{all $i$ and $S(i, t)$ for $i=$ gauge and all $t$ (Figure 5). The seasonal data is specified for the sub-basin that} contained the USGS gauge station, since all $S(i, t)$ are highly correlated (Correlations $\geq 0.8$ ). Given these circumstances, $S$ (gauge, $t$ )changes with Julian days and does not change spatially for each sampling location. This linear regression analysis (eq. 4) explained approximately $54 \%$ of $y(i, t)$, DOC concentrations for all samples (crop and non-crop, $\mathrm{R}^{2}{ }_{\text {adj }}=0.503, \mathrm{~N}=100$ ) as displayed in Figure 7 (both yellow and blue points). For crop dominant drainage sub-basins, the model explained approximately $50.44 \%\left(\mathrm{R}_{\text {adj }}^{2}=0.46, \mathrm{~N}=63\right.$, yellow triangle points $)$.

$$
f(X, S)=0.46 c r p+0.95 f r t+0.51 w e t l+15.1 d u m+1.25 p e t+0.046 s w-1.68 g w-59.96
$$

All seven variables in eq. 4 tested significant (p-value $<<0.05)$. The coefficients of eq. 4 likely indicate several responsive processes. The coefficients of the spatial variables have similar value ranges

413 to those associated with eq. 3, albeit with the exclusion of the variable $\operatorname{Ln}(A)$. The $\operatorname{Ln}(A)$ variable with 414 eq. 3 was functionally replaced by the ground water variable $(g w)$ in this finer spaciotemporal-scale 415 statistical analysis (eq. 4). The negative coefficient for $g w$ indicates an inverse relationship to DOC 416 observations. Logically, the presence of significant amounts of ground water is likely strongly correlated 417 to the size of the drainage area. The presence of relatively high groundwater amounts within larger sub- 
418 basins likely acts to dilute soil-profile DOC concentrations. These four spatial variables help to inform 419 what, where, and how land surface characteristics impact the variation of riverine DOC.

The three seasonal/temporal variables indicate that the timing (when) of increased DOC

421 concentrations is inherently related to the potential harm of the receiving aquatic ecosystem if DOC

422 exceeds ecosystem capacities. The coefficients of the three seasonal variables are nearly of equal

423 importance in this model. The hydrologic properties represented by these seasonal variables were

424 simulated well by the SWAT model. The modelled data values marked with light blue vertical lines in 425 Figure 7 are shown with their associated Julian days of DOC sample collection. The higher snowmelt 426 modelled with SWAT is consistent with the idea that these meltwaters infiltrate the soil and increase soil 427 water content $(s w)$ and thus carbon transport in the early months of the year (Figure 5).

The resultant coefficients and listed significant variables reflect underlying scientific rationales 430 rather than pure empirical analysis. The results indeed provide substantial information and knowledge 431 about the future development of a non-linear analytical model for exploring spatial and temporal 432 variations of DOC export. This statistical analysis of the variation of daily DOC concentrations also 433 implicated the necessity of extending the anticipated non-linear analytical model to incorporate seasonal 434 trends that would ultimately be helpful in analyzing the long-term anthropogenic effects on receiving 435 water DOC concentrations. For this purpose, we expand the statistical analysis to mean monthly DOC 436 concentrations in the following section.

\section{A quantitative analysis of mean monthly DOC trend}

Modelled daily DOC concentrations were averaged for each month from all 10 sampling locations in 440 which drainage sub-basins were crop dominated, $1^{\text {st }}$-order extended sub-basins. The mean monthly 
441 modelled DOC concentrations explained about $81 \%\left(\mathrm{R}^{2}=0.81\right)$ for the observation data set $1(\mathrm{Ob} 1$ in

442 Figure 8) for six months (i.e., Jan., Mar., Apr., May, Nov., and Dec.). The months related to Ob1 were 443 chosen because they represented data generated with more frequent field visits. The observation data 444 set2 (Ob2) were collected during summer months (i.e. Jun, Jul., Aug., and Sep.) and were limited in 445 sample frequency. Therefore, the model explained less (49\%) in correspondence analysis for the Ob2

446 months. In general, the model explained approximately $56 \%\left(\mathrm{R}^{2}=0.56\right)$ of the observations $(\mathrm{Ob} 1$ and 447 Ob2) throughout the year.

Monthly intervals are appropriate to both hindcast or forecast long-term impacts of climate change 450 and human activity on carbon-cycling processes. Our analysis suggests that monthly DOC 451 concentrations are indeed quantifiable and can provide an ideal baseline for developing next-generation 452 analytical models. The month-based, baseline model can provide a platform for including event-based 453 DOC fluctuations (Qiao et al. 2017). Such monthly, next-generation models can then be expanded to 454 incorporate both the spatial and temporal variables influencing DOC dynamics at sub-basin scales. 455 Ultimately, such models can integrate biological and physical processes to help identify where, when, 456 and how DOC source and transport mechanisms respond to climatic and anthropogenic processes.

\section{CONCLUSIONS}

459 Our research reported several analysis results of DOC cycling processes from croplands to 460 receiving waters. The spatiotemporal distributions of DOC concentrations were observed from a 461 cropland representative of the Midwestern United States. The main contributions of our research efforts 462 are summarized below. 
463 - The elevated DOC export rates in early spring were in response to snowpacks and snowmelt

464 processes over croplands with corn plant residue accumulation.

465 - Baseflow plays an important role in driving seasonal changes in DOC concentrations across spatial $466 \quad$ scales.

467 - The $1^{\text {st }}$-order extended drainage sub-basins are indeed an appropriate spatial scale for quantifying the 468 inherent relationship between independent variables and DOC concentrations in cropland areas.

469 - Integrating an appropriate LULC reclassification, hydrological processes, and systematic analysis of 470 geospatial and temporal features is indeed a viable approach for understanding DOC dynamics from $471 \quad$ agricultural landscapes with lowland hydrology.

472

473 Acknowledgements

474 This study is supported by a collaborative NSF Grant (1025547, PI: Q. Yu; 1025546, PI: Y.Q. Tian). 475 We would like to thank Ashley Blunden (Lowran) for completing the bulk of the field sampling as part 476 of her graduate work at CMU and Donald Uzarski for making his laboratory services available to 477 process our DOC samples. All supporting data have been listed in a pdf file that can be downloaded at: $478 \quad$ http://people.se.cmich.edu/tian2y/onlinedata.pdf 
481 Ågren, A., Haei, M., Köhler, S., Bishop, K., \& Laudon, H. (2010). Regulation of stream water dissolved 482 organic carbon (DOC) concentrations during snowmelt; the role of discharge, winter climate and 483 memory effects. Biogeosciences, 7, 2901-2913

484 Ågren, A., Jansson, M., Ivarsson, H., Bishop, K., \& Seibert, J. (2008). Seasonal and runoff-related changes in total organic carbon concentrations in the River Öre, Northern Sweden. Aquatic Sciences, 70, 21-29 Aitkenhead-Peterson, J.A., McDowell, W.H., \& Neff, J.C. (2003). Sources, production, and regulation of allochthonous dissolved organic matter inputs to surface waters. Aquatic ecosystems (pp. 25-70): Elsevier Arnold, J.G., \& Fohrer, N. (2005). SWAT2000: current capabilities and research opportunities in applied watershed modelling. Hydrological Processes: An International Journal, 19, 563-572

Bhattacharya, R., \& Osburn, C.L. (2020). Spatial patterns in dissolved organic matter composition controlled by watershed characteristics in a coastal river network: The Neuse River Basin, USA. Water Research, 169, 115248

Bowering, K.L., Edwards, K.A., Prestegaard, K., Zhu, X., \& Ziegler, S.E. (2020). Dissolved organic carbon mobilized from organic horizons of mature and harvested black spruce plots in a mesic boreal region. Biogeosciences, 17, 581-595

Butman, D., \& Raymond, P.A. (2011). Significant efflux of carbon dioxide from streams and rivers in the United States. In, Nature Geoscience (pp. 839-842) Clark, J.M., Lane, S.N., Chapman, P.J., \& Adamson, J.K. (2007). Export of dissolved organic carbon from an upland peatland during storm events: Implications for flux estimates. Journal of Hydrology, 347, 438-447

Confesor Jr, R.B., \& Whittaker, G.W. (2007). Automatic Calibration of Hydrologic Models With Multi Objective Evolutionary Algorithm and Pareto Optimization 1. JAWRA Journal of the American Water Resources Association, 43, 981-989

Du, X., Zhang, X., Mukundan, R., Hoang, L., \& Owens, E.M. (2019). Integrating terrestrial and aquatic processes toward watershed scale modeling of dissolved organic carbon fluxes. Environmental pollution, 249, 125-135

Dusek, J., Vogel, T., Dohnal, M., Barth, J.A., Sanda, M., Marx, A., \& Jankovec, J. (2017). Dynamics of dissolved organic carbon in hillslope discharge: Modeling and challenges. Journal of Hydrology, 546, 309-325 Ellis, E.C., Klein Goldewijk, K., Siebert, S., Lightman, D., \& Ramankutty, N. (2010). Anthropogenic transformation of the biomes, 1700 to 2000. Global ecology and biogeography, 19, 589-606 Fu, B., Merritt, W.S., Croke, B.F., Weber, T.R., \& Jakeman, A.J. (2019). A review of catchment-scale water quality and erosion models and a synthesis of future prospects. Environmental modelling \& software, 114, 75-97

Futter, M., Löfgren, S., Köhler, S., Lundin, L., Moldan, F., \& Bringmark, L. (2011). Simulating dissolved organic carbon dynamics at the Swedish integrated monitoring sites with the integrated catchments model for carbon, INCA-C. Ambio, 40, 906-919 Gómez - Gener, L., Hotchkiss, E.R., Laudon, H., \& Sponseller, R.A. (2021). Integrating Discharge Concentration Dynamics Across Carbon Forms in a Boreal Landscape. Water Resources Research, 57, e2020WR028806 
Guo, R., Qin, W., Jiang, C., Kang, L., Nendel, C., \& Chen, Q. (2018). Sweet corn significantly increases nitrogen retention and reduces nitrogen leaching as summer catch crop in protected vegetable production systems. Soil and Tillage Research, 180, 148-153

Haaland, S., \& Mulder, J. (2010). Dissolved organic carbon concentrations in runoff from shallow heathland catchments: effects of frequent excessive leaching in summer and autumn. Biogeochemistry, 97, 45-53 Heppell, C.M., Binley, A., Trimmer, M., Darch, T., Jones, A., Malone, E., Collins, A.L., Johnes, P.J., Freer, J.E., \& Lloyd, C.E. (2017). Hydrological controls on DOC: nitrate resource stoichiometry in a lowland, agricultural catchment, southern UK. Hydrology and Earth System Sciences, 21, 4785-4802 Holgerson, M.A., \& Raymond, P.A. (2016). Large contribution to inland water CO 2 and CH 4 emissions from very small ponds. In, Nature Geoscience (pp. 222-226)

Jones, J., Knowlton, M., Obrecht, D., \& Cook, E. (2004). Importance of landscape variables and morphology on nutrients in Missouri reservoirs. In, Canadian Journal of Fisheries and Aquatic Sciences (pp. 1503-1512) Jones, J.R., \& Knowlton, M.F. (2005). Suspended solids in Missouri reservoirs in relation to catchment features and internal processes. In, Water Research (pp. 3629-3635)

Kellerman, A.M., Arellano, A., Podgorski, D.C., Martin, E.E., Martin, J.B., Deuerling, K.M., Bianchi, T.S., \& Spencer, R.G. (2020). Fundamental drivers of dissolved organic matter composition across an Arctic effective precipitation gradient. Limnology and Oceanography, 65, 1217-1234

Kelly, V., Stets, E.G., \& Crawford, C. (2015). Long-term changes in nitrate conditions over the 20th century in two Midwestern Corn Belt streams. Journal of Hydrology, 525, 559-571 Leakey, A.D., Uribelarrea, M., Ainsworth, E.A., Naidu, S.L., Rogers, A., Ort, D.R., \& Long, S.P. (2006). Photosynthesis, productivity, and yield of maize are not affected by open-air elevation of $\mathrm{CO} 2$ concentration in the absence of drought. Plant physiology, 140, 779-790 Lehosmaa, K., Jyväsjärvi, J., Ilmonen, J., Rossi, P.M., Paasivirta, L., \& Muotka, T. (2018). Groundwater contamination and land drainage induce divergent responses in boreal spring ecosystems. Science of the Total Environment, 639, 100-109

Li, J., Yu, Q., Tian, Y.Q., \& Boutt, D.F. (2018). Effects of landcover, soil property, and temperature on covariations of DOC and CDOM in inland waters. Journal of Geophysical Research: Biogeosciences, 123, 1352-1365

Lindström, G., Pers, C., Rosberg, J., Strömqvist, J., \& Arheimer, B. (2010). Development and testing of the HYPE (Hydrological Predictions for the Environment) water quality model for different spatial scales. Hydrology research, 41, 295-319

Millie, D.F., Weckman, G.R., Pigg, R.J., Tester, P.A., Dyble, J., Wayne Litaker, R., Carrick, H.J., \& Fahnenstiel, G.L. (2006). MODELING PHYTOPLANKTON ABUNDANCE IN SAGINAW BAY, LAKE HURON: USING ARTIFICIAL NEURAL NETWORKS TO DISCERN FUNCTIONAL INFLUENCE OF ENVIRONMENTAL VARIABLES AND RELEVANCE TO A GREAT LAKES OBSERVING SYSTEM 1. Journal of phycology, 42, 336349

Monaghan, R., Wilcock, R., Smith, L., Tikkisetty, B., Thorrold, B., \& Costall, D. (2007). Linkages between land management activities and water quality in an intensively farmed catchment in southern New Zealand. In, Agriculture, Ecosystems \& Environment (pp. 211-222) Motavalli, P., Bundy, L., Andraski, T., \& Peterson, A. (1992). Residual effects of long - term nitrogen fertilization on nitrogen availability to corn. Journal of production agriculture, 5, 363-368 
Oberle, S., \& Keeney, D. (1990). Factors influencing corn fertilizer N requirements in the northern US corn belt. Journal of production agriculture, 3, 527-534 Olaoye, I.A., Confesor, R.B., \& Ortiz, J.D. (2021). Effect of projected land use and climate change on water quality of Old Woman Creek Watershed, Ohio. Hydrology, 8, 62 Olsson, M.T., Erlandsson, M., Lundin, L., Nilsson, T., Nilsson, Å., \& Stendahl, J. (2009). Organic carbon stocks in Swedish Podzol soils in relation to soil hydrology and other site characteristics. Silva Fennica, 43, 209-222

Pers, C., Temnerud, J., \& Lindström, G. (2016). Modelling water, nutrients, and organic carbon in forested catchments: a HYPE application. Hydrological Processes, 30, 3252-3273 Puczko, K., Zieliński, P., Jusik, S., Kołakowska, A., \& Jekatierynczuk-Rudczyk, E. (2018). Vascular plant and bryophyte species richness in response to water quality in lowland spring niches with different anthropogenic impacts. Environmental monitoring and assessment, 190, 1-16 Qiao, H., Tian, Y.Q., Yu, Q., Carrick, H.J., Francek, M., \& Li, J. (2017). Snowpack enhanced dissolved organic carbon export during a variety of hydrologic of events in an agricultural landscape, Midwestern USA. In, Agricultural and Forest Meteorology (pp. 31-41)

Raymond, P.A., \& Saiers, J.E. (2010). Event controlled DOC export from forested watersheds. Biogeochemistry, 100, 197-209 Rudolph, J.C., Arendt, C.A., Hounshell, A.G., Paerl, H.W., \& Osburn, C.L. (2020). Use of geospatial, hydrologic, and geochemical modeling to determine the influence of wetland-derived organic matter in coastal waters in response to extreme weather events. Frontiers in Marine Science, 7, 18 Sela, S., Woodbury, P., Marjerison, R., \& van Es, H. (2019). Towards applying N balance as a sustainability indicator for the US Corn Belt: realistic achievable targets, spatio-temporal variability and policy implications. Environmental Research Letters, 14, 064015 Sharratt, B., Benoit, G., \& Voorhees, W. (1998). Winter soil microclimate altered by corn residue management in the northern Corn Belt of the USA. Soil and Tillage Research, 49, 243-248

Singh, S., Inamdar, S., \& Mitchell, M. (2015). Changes in dissolved organic matter (DOM) amount and composition along nested headwater stream locations during baseflow and stormflow. Hydrological Processes, 29, 1505-1520

Spencer, R.G., Aiken, G.R., Dornblaser, M.M., Butler, K.D., Holmes, R.M., Fiske, G., Mann, P.J., \& Stubbins, A. (2013). Chromophoric dissolved organic matter export from US rivers. Geophysical Research Letters, 40, 1575-1579

Stedmon, C.A., Markager, S., Søndergaard, M., Vang, T., Laubel, A., Borch, N.H., \& Windelin, A. (2006). Dissolved organic matter (DOM) export to a temperate estuary: seasonal variations and implications of land use. Estuaries and Coasts, 29, 388-400

Tian, Y.Q., Gong, P., Radke, J.D., \& Scarborough, J. (2002). Spatial and temporal modeling of microbial contaminants on grazing farmlands. Journal of Environmental Quality, 31, 860-869

Tian, Y.Q., Wang, D., Chen, R.F., \& Huang, W. (2012). Using modeled runoff to study DOC dynamics in stream and river flow: A case study of an urban watershed southeast of Boston, Massachusetts. Ecological Engineering, 42, 212-222

Tranvik, L. (2014). Carbon cycling in the Arctic. In, Science (pp. 870-870) Valentin, C., Agus, F., Alamban, R., Boosaner, A., Bricquet, J.-P., Chaplot, V., De Guzman, T., De Rouw, A., Janeau, J.-L., \& Orange, D. (2008). Runoff and sediment losses from 27 upland catchments in Southeast Asia: Impact of rapid land use changes and conservation practices. Agriculture, Ecosystems \& Environment, 128, 225-238 
610 Vetsch, J.A., \& Randall, G.W. (2002). Corn production as affected by tillage system and starter fertilizer. 611 Agronomy Journal, 94, 532-540

612 Vlahos, P., Chen, R.F., \& Repeta, D.J. (2002). Dissolved organic carbon in the Mid-Atlantic Bight. Deep

613 Sea Research Part II: Topical Studies in Oceanography, 49, 4369-4385

614

615 


\section{Statements \& Declarations}

617 This study is supported by a collaborative NSF Grant (1025547, PI: Q. Yu; 1025546, PI: Y.Q. Tian). 618 
619 Author Contributions

620 1. Research concept, design, and question

621 All authors

622 2. Funding:

623

624

Yong Tian, Qian Yu, Hunter Carrick

625

626

627

628

629

630

631

3. Material preparation, and data collection

Yong Tian, Qian Yu, Hunter Carrick, Brain Becker, and Remegio Confesor

4. Data analyses

Yong Tian, Qian Yu, and Anderson, C. Olivia

5. Manuscript preparation and Final Manuscript Approval

All authors 
Figure and table captions

633 Figure 1, The primary study area and landcover. It consists of 21 sampling locations established at sub634 basin outlets of the drainage sub-basins. Black polygons are the drainage sub-basins. The blue vector data are the streams. (Color needed)

Figure 2, Original national land cover classification codes (NLCD) and three newly formed classes.

637 Figure 3, A) the linear regression estimation against the DOC observations, and B) both Crop\% and 638 $\mathrm{Ln}(\mathrm{A})$ have inverse correlations to DOC concentrations, yet the correlation between Crop\% and $\operatorname{Ln}(\mathrm{A})$ is positive.

640 Figure 4, A): Mean monthly DOC concentrations for Crop and mixed land covers over the primary 641 study site. Note that February DOC concentrations were interpolated by using the average value of adjacent months. B): Monthly mean DOC concentrations of five sub-basins in the Connecticut River Watershed collected in years 2011-2016. Note that February and July data were interpolated by averaging data from the jacent months. In general, mean monthly DOC

647 Figure 5, SWAT modelled daily PET, SW, SN, GW and SM for sub-basin 49 for year 2013. The subbasin 49 contains the USGS gage station. The dashed light blue vertical lines indicate the sampling date. (PET: Potential Evapotranspiration, SW: Soil Water content, GW: ground water, and Snowmelt: Snow Liquid Equivalent). 
651 Figure 6, DOC production rates of three vegetation types: corn plant (AH/AL), broad leaf liters 652 (DH/DL) and conifer leaf liters (EH/EL). The L stands for low temperature $\left(20^{\circ} \mathrm{C}\right)$ and $\mathrm{H}$ is $653 \quad$ the high temperature $\left(25^{\circ} \mathrm{C}\right)$

654 Figure 7, the modelled (Y axis) versus observed (X axis) DOC concentrations for all data points 655 collected over enhanced-area landscapes $(\mathrm{N}=100)$, and for crop dominant drainage areas 656 (yellow triangle points, $\mathrm{N}=63$ ).

657 Figure 8, Modelled (mod in red) versus observed mean monthly DOC concentrations for crop dominant 658 drainage areas over 1st-order drainage sub-basins. Observation data set 1 (Ob1) is for Jan, Mar, 659 Apr, May, Oct, Nov, and Dec, R2=0.81. Observation data set 2 (Ob2) is for Jun, Jul, Aug, and 660 Sep, R2 $=0.49$. For combined Ob1 \& Ob2 in all 12 months together, R2 $>0.56$

661 Table 1, Land Use Composition (\%) in the area (Cells) draining to each sample location (SID). Crop\%: 662 percent of crop coverage, Fort\%: Forest, Wet1\%: wetlands, Dev\%: developed, and wat\%: Water body. 


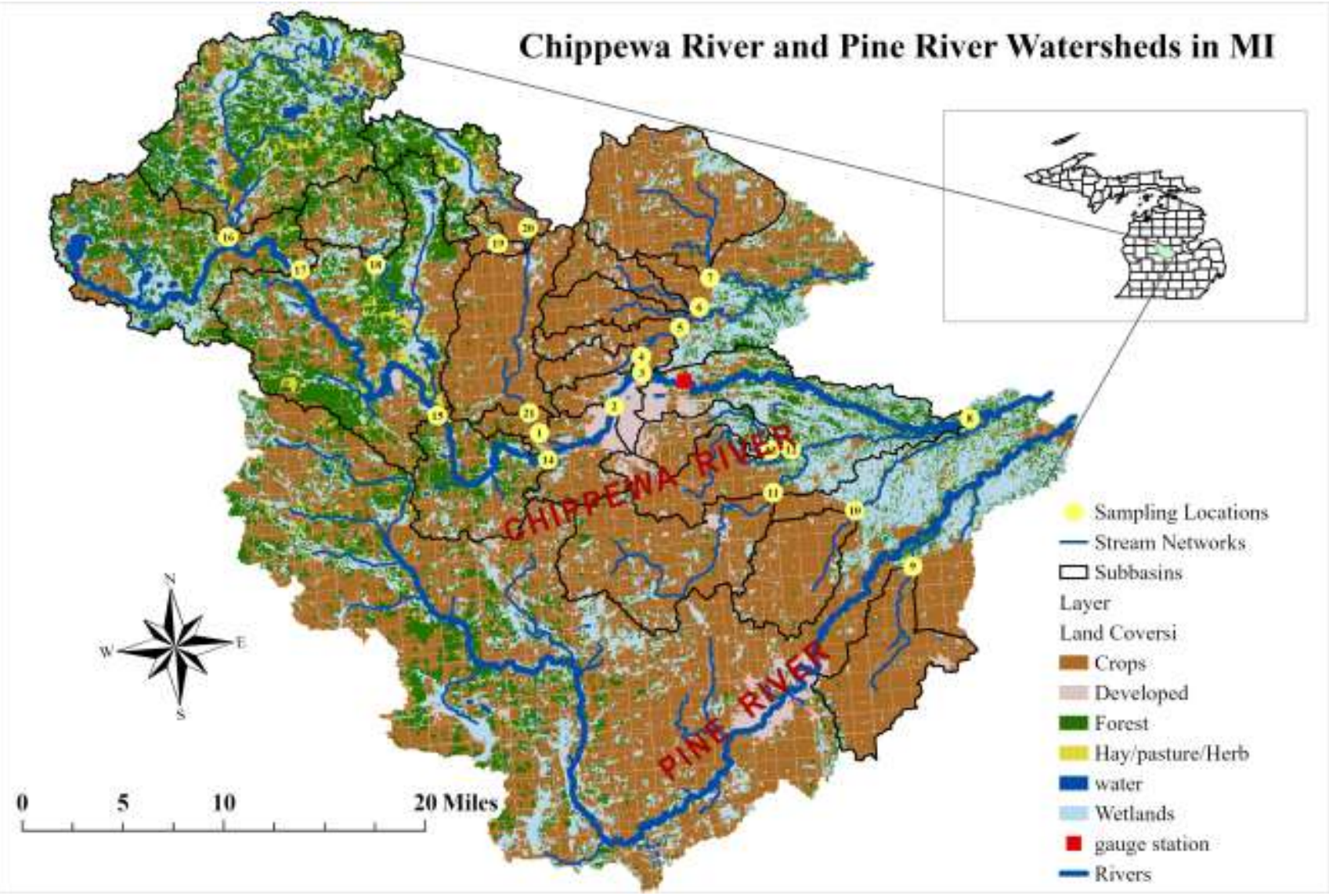

Figure 2, The primary study area and landcover. It consists of 21 sampling locations established 670 at sub-basin outlets of the drainage sub-basins. Black polygons are the drainage sub-basins. The blue 671 vector data are the streams. 


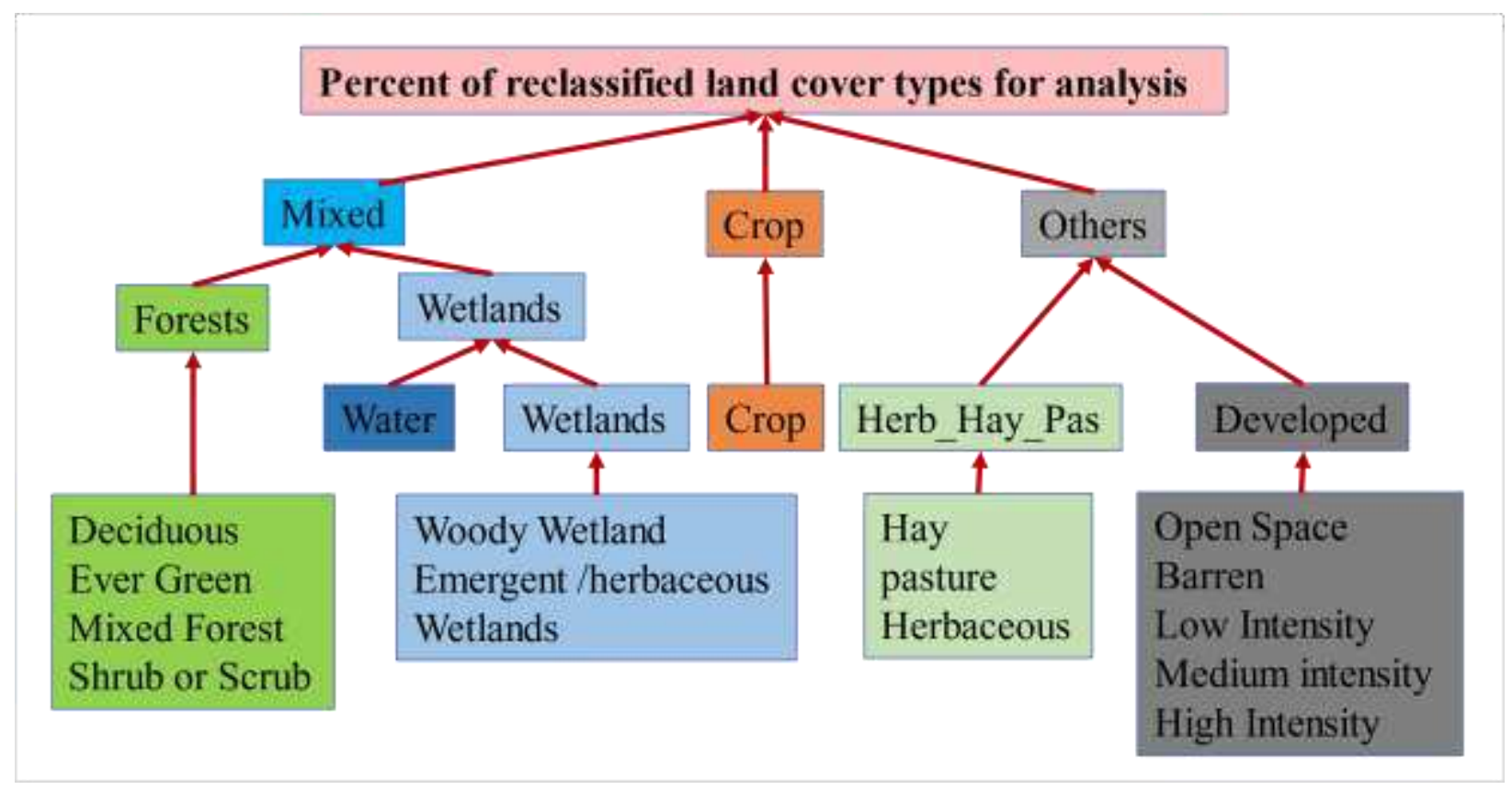

675

Figure 3, Original national land cover classification codes (NLCD) and three newly formed classes.

677 

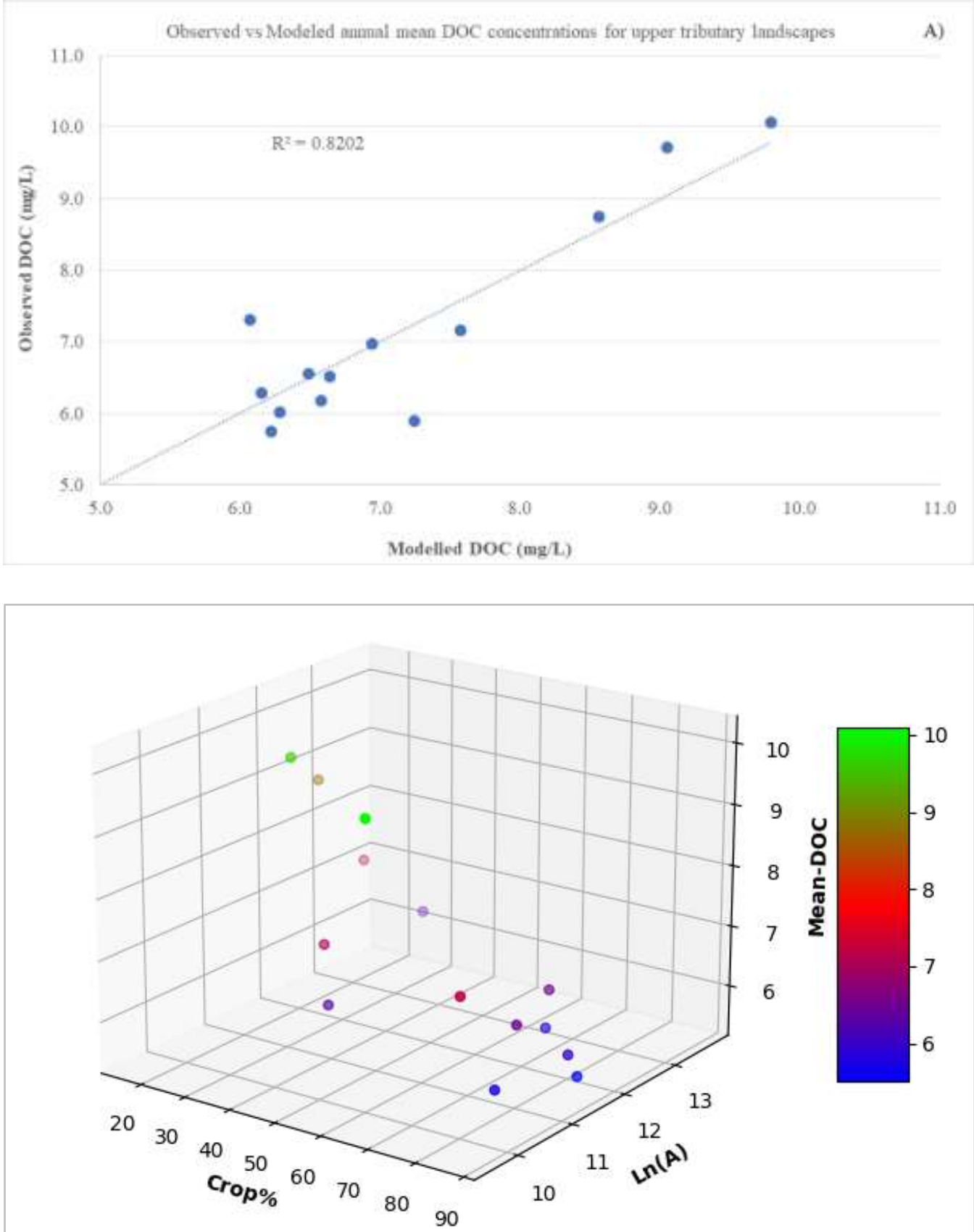

Figure $4, A$ ) the linear regression estimation against the DOC observations, and $B)$ both Crop\% and $\operatorname{Ln}(A)$ have inverse correlations to DOC concentrations, yet the correlation between Crop $\%$ and $\operatorname{Ln}(A)$ is positive.

683

684 

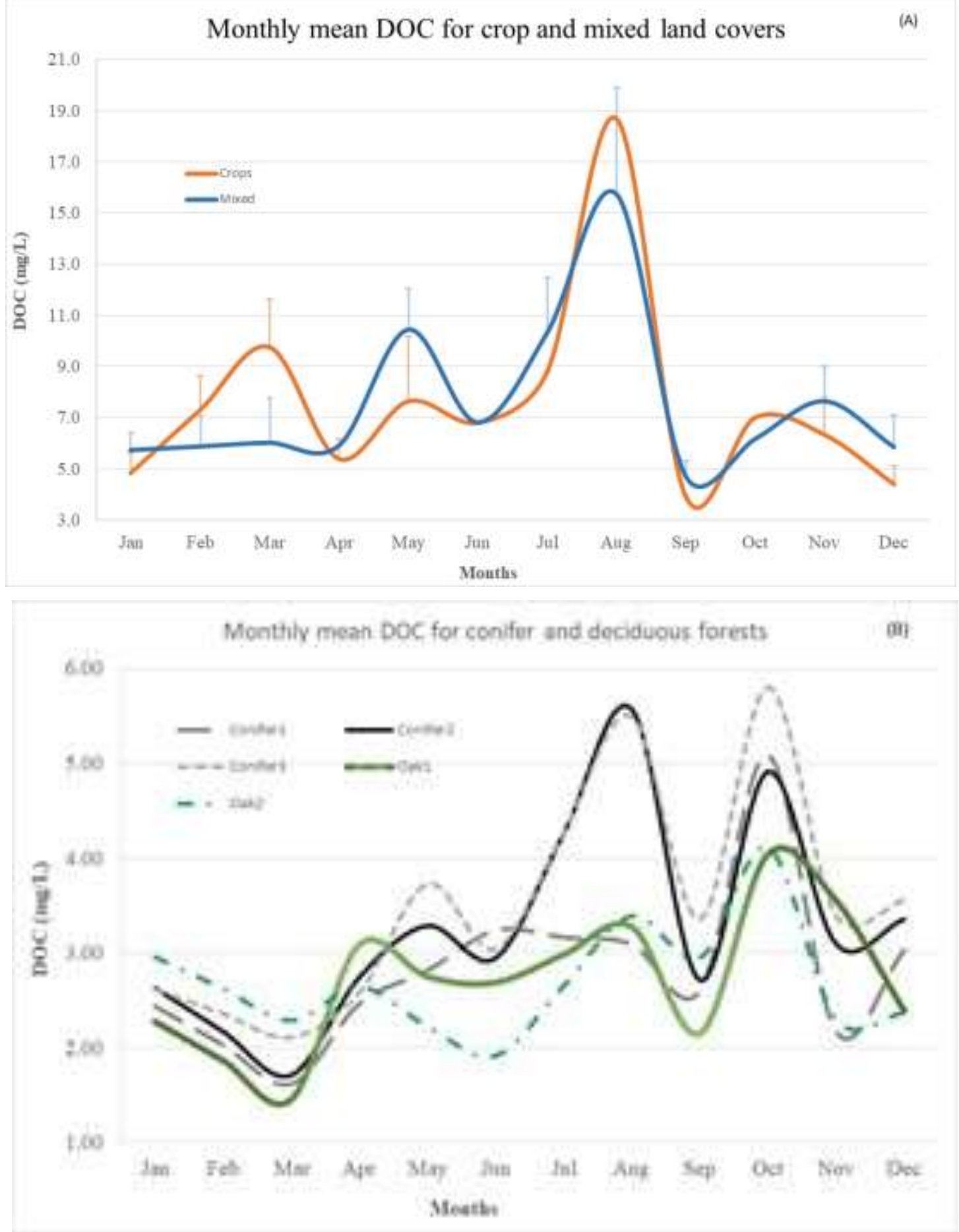

Figure 5, A): Mean monthly DOC concentrations for Crop and mixed land covers over the primary study site. Note that February DOC concentrations were interpolated by using the average value of adjacent months. B): Monthly mean DOC concentrations of five subbasins in the Connecticut River Watershed collected in years 2011-2016. Note that February and July data were interpolated by averaging data from the jacent months. In general, mean monthly DOC from croplands in the Chippewa River Watershed are highly correlated (0.65) to that from forested area in the Connecticut River Watershed. 


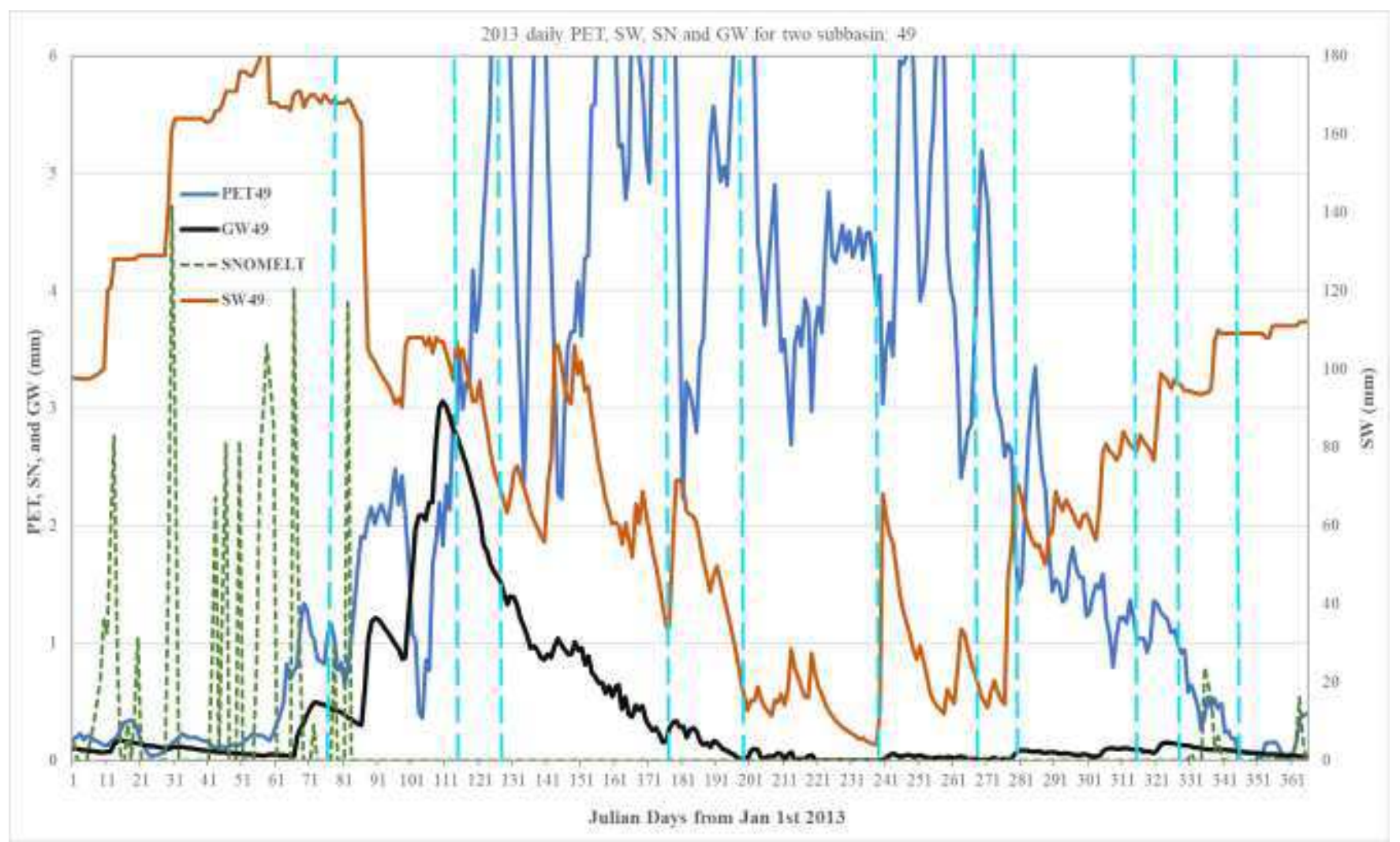

694

695

696

697

698

699

Figure 6, SWAT modelled daily PET, SW, SN, GW and SM for subbasin 49 for year 2013. The subbasin 49 contains the USGS gage station. The dashed light blue vertical lines indicate the sampling date. (PET: Potential Evapotranspiration, SW: Soil Water content, GW: ground water, and Snowmelt: Snow Liquid Equivalent). 
701

702

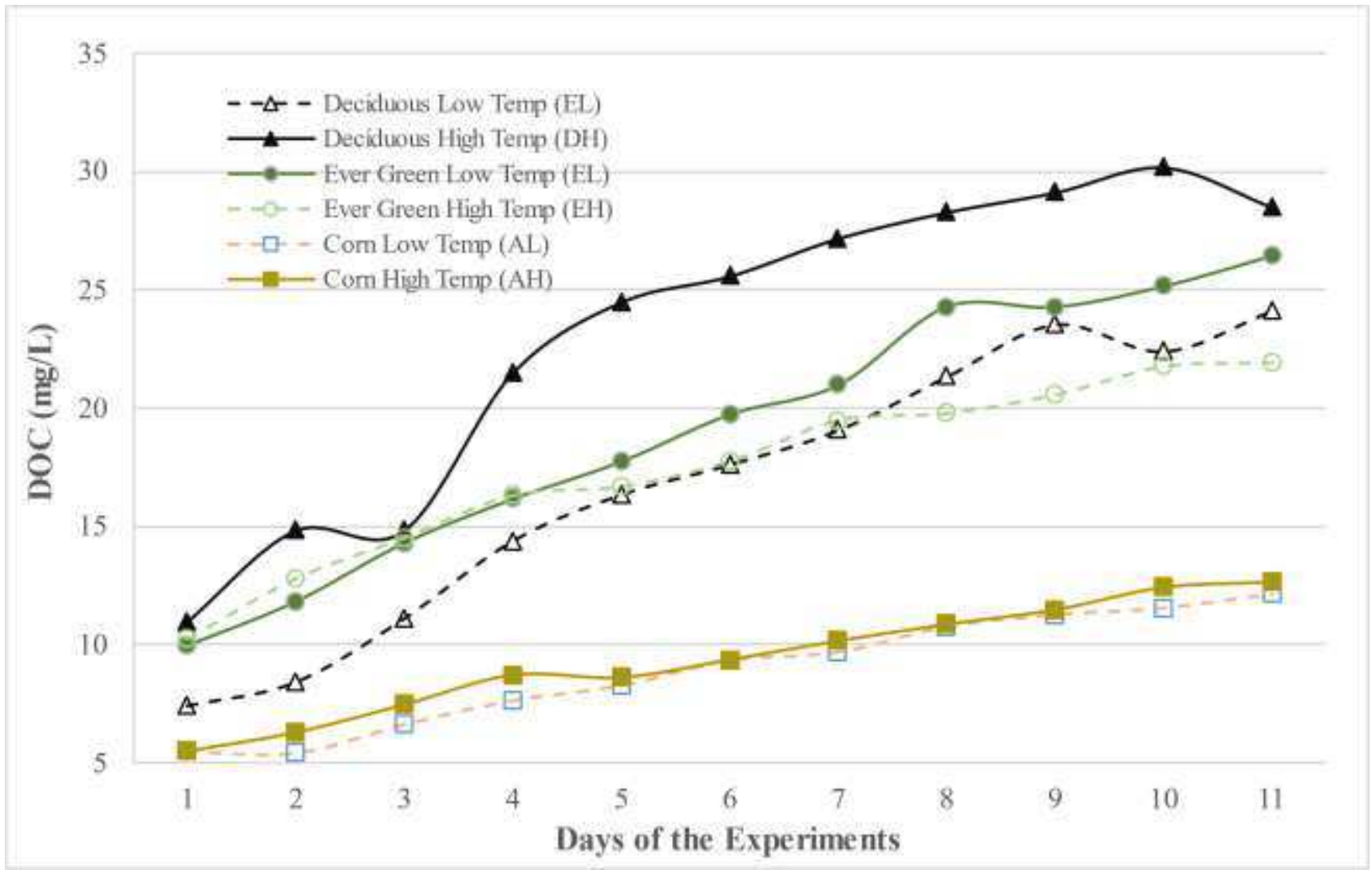

Figure 7, DOC production rates of three vegetation types: corn plant (AH/AL), broad leaf liters (DH/DL) and conifer leaf liters (EH/EL). The $\mathrm{L}$ stands for low temperature $\left(20^{\circ} \mathrm{C}\right)$ and $\mathrm{H}$ is the high temperature $\left(25^{\circ} \mathrm{C}\right)$ 


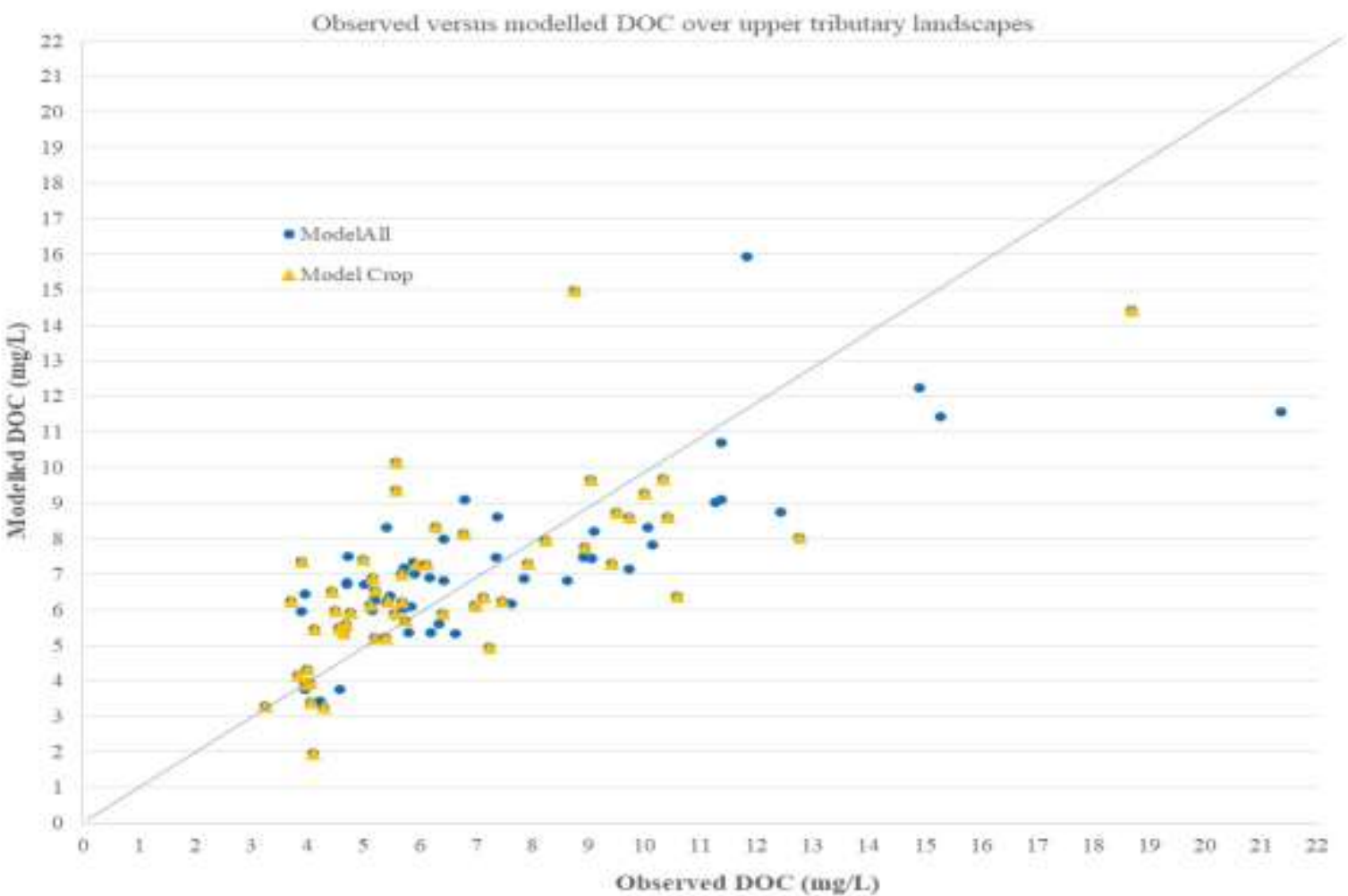

Figure 8, the modelled ( $\mathrm{Y}$ axis) versus observed ( $\mathrm{X}$ axis) DOC concentrations for all data points collected over enhanced-area landscapes $(\mathrm{N}=100)$, and for crop dominant drainage areas (yellow triangle points, $\mathrm{N}=63$ ).

707

708

709 


\section{Modelled Monthly DOC concentrations against observed}

20

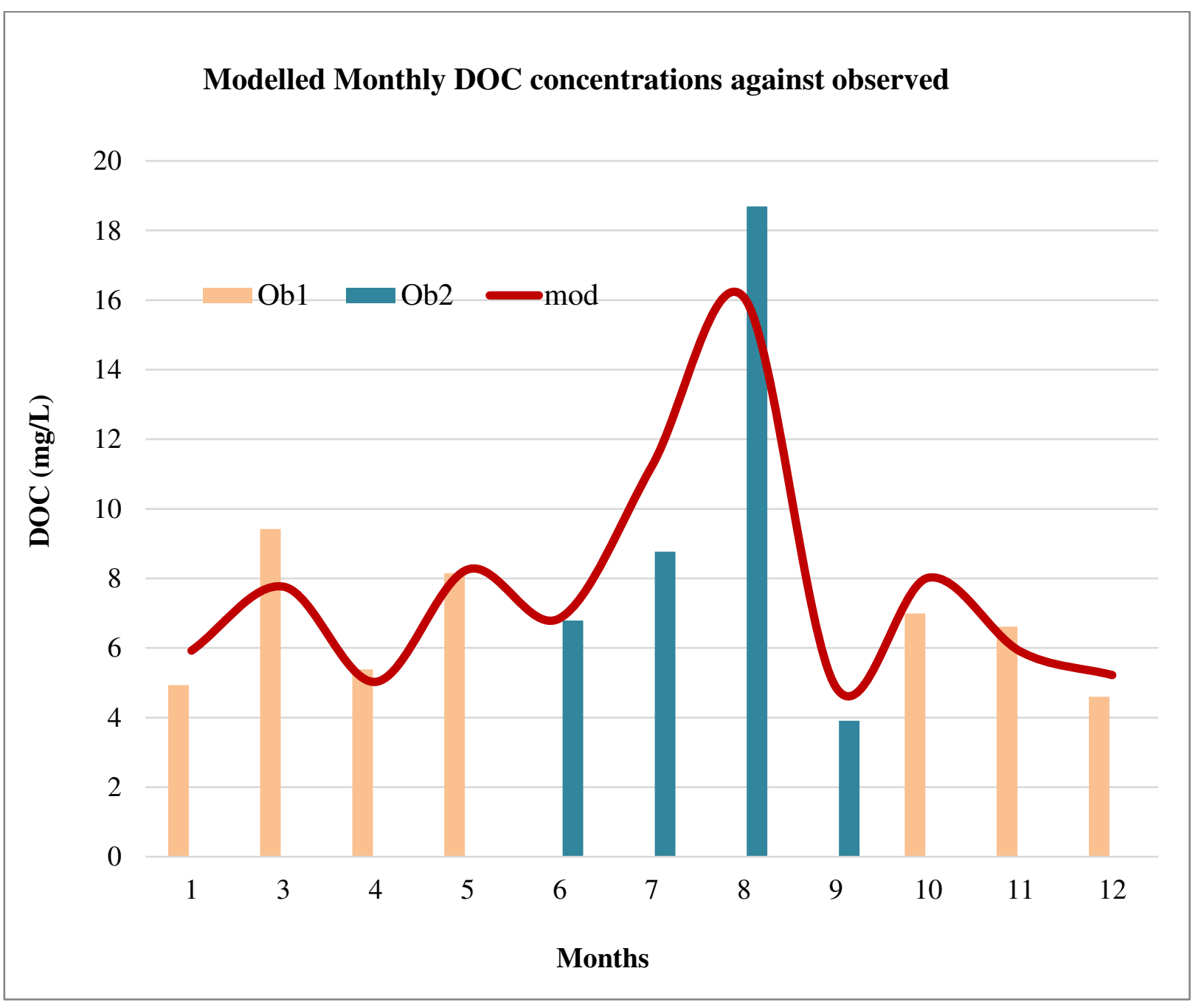

\section{Months}

Figure 9, Modelled (mod in red) versus observed mean monthly DOC concentrations for crop dominant drainage areas over $1^{\text {st }}$-order drainage subbasins. Observation data set $\mathbf{1}(\mathrm{Ob} 1)$ is for Jan, Mar, Apr, May, Oct, Nov, and Dec, $\mathbf{R}^{2}=\mathbf{0 . 8 1}$. Observation data set $\mathbf{2}$ (Ob2) is for Jun, Jul, Aug, and Sep, R2 = 0.49. For combined Ob1 \& Ob2 in all 12 months together, $R^{2}>0.56$

\section{6} 7 
Table 1, Land Use Composition (\%) in the area (Cells) draining to each sample location (SID).

721 Crop\%: percent of crop coverage, Fort\%: Forest, Wetl\%: wetlands, Dev\%: developed, and wat\%: Water 722 body.

\begin{tabular}{|c|c|c|c|c|c|c|c|c|c|c|}
\hline ID & $\begin{array}{c}\text { Samples } \\
\#\end{array}$ & $\begin{array}{l}\text { DOC } \\
\mathrm{Mg} / \mathrm{L}\end{array}$ & Cells & Ln(Cells) & $\begin{array}{c}\text { Crop } \\
\%\end{array}$ & $\begin{array}{c}\text { Forest } \\
\%\end{array}$ & $\begin{array}{c}\text { Wetland } \\
\%\end{array}$ & $\begin{array}{c}\text { Developed } \\
\%\end{array}$ & $\begin{array}{c}\text { Hay } \\
\%\end{array}$ & $\begin{array}{c}\text { Water } \\
\%\end{array}$ \\
\hline 1 & 7 & 6.899 & 259437 & 12.47 & 64 & 16 & 13 & 5 & 3 & 0 \\
\hline 2 & 7 & 5.864 & 1402613 & 14.15 & 38 & 29 & 18 & 8 & 4 & 2 \\
\hline 3 & 6 & 6.009 & 1435616 & 14.18 & 37 & 16 & 15 & 29 & 2 & 1 \\
\hline 4 & 6 & 7.300 & 26314 & 10.18 & 78 & 3 & 12 & 7 & 0 & 0 \\
\hline 5 & 6 & 6.548 & 61578 & 11.03 & 80 & 3 & 11 & 6 & 0 & 0 \\
\hline 6 & 6 & 5.739 & 38201 & 10.55 & 81 & 3 & 8 & 7 & 0 & 0 \\
\hline 7 & 6 & 6.503 & 176446 & 12.08 & 75 & 4 & 14 & 6 & 1 & 0 \\
\hline 8 & 7 & 6.263 & 1915023 & 14.47 & 39 & 18 & 26 & 14 & 3 & 1 \\
\hline 9 & 6 & 5.516 & 113370 & 11.64 & 86 & 2 & 3 & 8 & 1 & 0 \\
\hline 10 & 7 & 6.006 & 86448 & 11.37 & 87 & 2 & 6 & 5 & 0 & 0 \\
\hline 11 & 6 & 5.890 & 166695 & 12.02 & 75 & 5 & 13 & 7 & 0 & 0 \\
\hline 12 & 6 & 6.351 & 46173 & 10.74 & 26 & 24 & 33 & 12 & 5 & 0 \\
\hline 13 & 6 & 6.274 & 41969 & 10.64 & 44 & 12 & 24 & 17 & 1 & 1 \\
\hline 14 & 10 & 5.508 & 1079820 & 13.89 & 30 & 36 & 20 & 6 & 5 & 3 \\
\hline 15 & 10 & 6.166 & 966081 & 13.78 & 27 & 37 & 21 & 6 & 6 & 3 \\
\hline 16 & 10 & 8.736 & 327472 & 12.70 & 16 & 42 & 26 & 5 & 8 & 3 \\
\hline 17 & 9 & 7.159 & 550234 & 13.22 & 20 & 40 & 24 & 5 & 7 & 4 \\
\hline 18 & 10 & 6.972 & 62698 & 11.05 & 38 & 34 & 20 & 5 & 4 & 0 \\
\hline 19 & 4 & 10.057 & 13910 & 9.54 & 66 & 10 & 15 & 6 & 3 & 0 \\
\hline 20 & 8 & 9.704 & 91906 & 11.43 & 26 & 39 & 24 & 4 & 7 & 0 \\
\hline 21 & 10 & 8.318 & 244838 & 12.41 & 59 & 17 & 16 & 5 & 3 & 0 \\
\hline
\end{tabular}

